\title{
Preferences and Pattern of Information Seeking of Academics of Health Related Faculties, University of Peardeniya (UoP)
}

\author{
Perera, P.A.S.H ${ }^{1}$
}

\begin{abstract}
The objectives of the study is to 1) identify the preferences and information seeking behavior of the academics of health related faculties of UOP, 2) examine how they manage their information needs and 3) make recommendations for appropriate changes for future use. The study population consisted of all the academics (173) of four faculties, Allied Health Sciences (FAHS), Dental Sciences (FDS), Medicine (FM) and Veterinary Medicine \& Animal Sciences (FVMAS). An online survey questionnaire was used to gather data from the sample. The strategies used by the respondents in their information needs were: use of library $(24 \%)$, Internet $(100 \%)$, databases through library web page (59\%) and personal collections of resources (76\%). Purposes of seeking information by majority (90\%) were; teaching, research, updating knowledge and writing articles while percentages of that for 'managing patients' and 'clinical information' varied according to designation and faculty of the respondents. $71 \%$ of lecturers used information for preparation of exams. Majority (81\%) of respondents used E-journals and Web-based information frequently. 'Google search' was used as the most useful search engine by $98 \%$ of all groups. HINARI was the most used database by $64.4 \%$ and Medline-PUBMED was the most used resource by $71.2 \%$. For updating knowledge, more than $90 \%$ of respondents used public/guest lectures, conferences/seminars, research sessions, and contacts with professional colleagues while $70 \%$ downloaded articles through colleagues abroad. As suggested through free comments and according to findings of the study, provision of university-wide online access to reputed journals and other essential resources, upgraded computers with fast connectivity and training programs on information literacy skills are recommended for future improvements.
\end{abstract}

Keywords: Medical information, information seeking behaviour, medical academics/scientists, Sri Lanka

\section{Introduction}

Technology offers many promises for enhancing access and use of various knowledgebased sources (Andrews, Pearce, Ireson and Love, 2005). With the increasing amount of health/medical information being available on the Internet a rapid growth in the knowledge-

\footnotetext{
${ }^{l}$ Senior Assistant Librarian, Faculty of Medicine, University of Peradeniya, Sri Lanka. Email: sriper@pdn.ac.lk
} 
base of the field of health/medical sciences has been evident. Thus, breadth and complexity of information and knowledge required in medical education, health/medical research and clinical practice is rapidly increasing. In this context, health information professionals in universities are compelled to change their role and redesign their services in order to meet the needs of their clients who are health professionals/scientists. In addressing this timely issue it is important to investigate the information seeking pattern and their preferences of this group of clients. Literature review reported no research on such a study carried out in the University of Peradeniya (UOP). The four faculties, Allied Health Sciences (FAHS), Dental Sciences (FDS), Medicine (FM) and Veterinary Medicine \& Animal Husbandry (FVMAH) were identified as health related faculties of the University of Peradeniya of which the academics who are health professionals/scientists and are involved in clinical practice and service functions in addition to their traditional role in teaching and research both at undergraduate and postgraduate levels. These academics included three groups by designation; professors, senior lecturers and lecturers. The objective of the study in this paper is to 1) identify the preferences and information seeking behavior of these academics, 2) to examine how they manage their information needs and 3) to make recommendations for appropriate changes in the existing system.

\section{Literature Review}

A study of relevance in the Sri Lankan context (participants were medical academics of the University of Peradeniya and doctors attached to Kandy and Peradeniya hospitals) is reported by Seneviratne, D. C.(2004). Findings of this study revealed that the prominent factor that motivated the information search was the need to be updated with new information and various channels of information where institutional library played a major role. Medical textbooks were the most widely used information resource while the participants were visibly depended on journal articles. It was further reported that medical scientists continued to rely on printed materials and apart from their institutional library, the most used library by all the respondents was the Medical Library of University of Peradeniya. Findings revealed that modern electronic resources were hardly used by 
majority of the respondents and the shift from the use of print to electronic formats was very slow.

In literature, several studies on similar topics can be found. Thain and Wales (2003) investigated the information needs and use of NHS(UK) library services by its members and found that there were indications of unmet needs for local contact information and evaluated patient information. Bennett, Casebeer, Robert, Kristofco, and Strasser (2004) reported that electronic media were viewed as increasingly important sources for clinical information, with decreased use of journals and local continuing medical education (CME).

In another study undertaken by Andrews et al. (2005), it was reported that participants (primary care practitioners) did not use online information resources as much as print and interpersonal resources and that the frequency of seeking information was fairly high, consistent with the studies noted earlier. Further he reported that time, cost, and skills emerged as major barriers to seeking information, albeit the respondents reported a fair level of use of available resources. Access to and use of a medical library of some sort was relatively strong as reported in this study. Hider, Griffin, Walker and Coughlan (2009) reported that people and text resources appeared to be favoured over electronic resources and that this has not changed over time, even though access to electronic resources has increased. On the other hand, van der Voort, Swenne, van der Hoorn-van Velthoven and Belt (2012) reported that academic teaching physicians accessed online resources daily in their consultation of medical literature, indicating a shift from library oriented information searching to Internet-based information searching in the present scenario of informationseeking behavior of academics/ scientists in the field of medicine/health sciences.

\section{Methodology}

A survey method was adopted using interviews and an online questionnaire (in English) which was specially designed and pre-tested to collect data that could be used to achieve the objectives of the study. The questionnaire consisted of nineteen main questions encompassing several subsidiary questions, which were all structured, thus close-ended 
including two dichotomous questions. Provision was however, made at the end of questionnaire for the respondents to express their views or opinions in a free flowing manner; intention was to gather true and insightful information on issues of interest to respondents. The study population consisted of all the academics of four health related faculties (173) which was also taken as the sample in this study. Ten academics randomly selected representing all groups were interviewed by telephone during working hours while they were in their departments. Questions asked during interviews covered some of the same issues of the questionnaire, though the type was open-ended. To maintain the confidentiality, answers gathered in interviews were coded to remove names and subsequently transcribed. Questionnaire was administered to all 173 academics through eelectronic mail in August 2013 and recipients were requested to respond and submit it back online. Two reminders were sent (electronic mail) with one week intervals before the deadline for submitting responses. Questions did not contain any issues that would cause any psychological and physiological trauma, thus, ethical clearance of any sort was not obtained. The survey was completely anonymous and collected only limited demographic data (gender, qualifications and designation). Responses which were automatically saved in a database were coded and data were analyzed using MINITAB (16). Cross-tabulation ( to obtain percentages) with Pearson Chi-Square approximation( to check the relationships between groups) and One-way ANOVA ( $\mathrm{p}<0.05)$ were used as appropriate statistical analysis procedures and Pearson Chi-Square values only when available at value of $\mathrm{P}<$ or $=0.05$ were taken into consideration.

\section{Results and Discussion}

\section{Profile of the Respondents:}

The percentage of respondents to the questionnaire was 34\% (59 out of 173). Response rate by faculty is shown in Figure 6.1.1. Majority of respondents was from Faculty of Medicine which is in line with the profile of the study sample/population. 
Intention of collecting demographic data was to study the profile of the respondents and to check if there is a relationship between groups in relation to their information seeking behavior. Demographic analysis of respondents is depicted in Figures 1, 2, 3 and 4. Majority of the respondents was female, senior lecturers by designation and had MBBS as the first degree. Of the total respondents, apart from their first degree $80 \%$ had higher degrees such as M.Phil, PhD, MD, MS, MRCOG, MRCP, FRC, FCP etc.

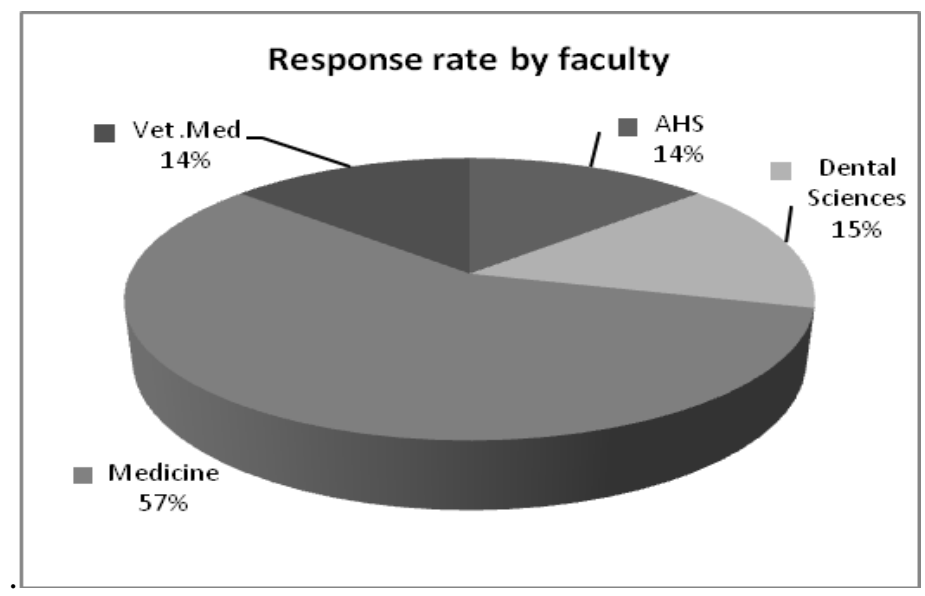

Figure 1: Response rate by faculty

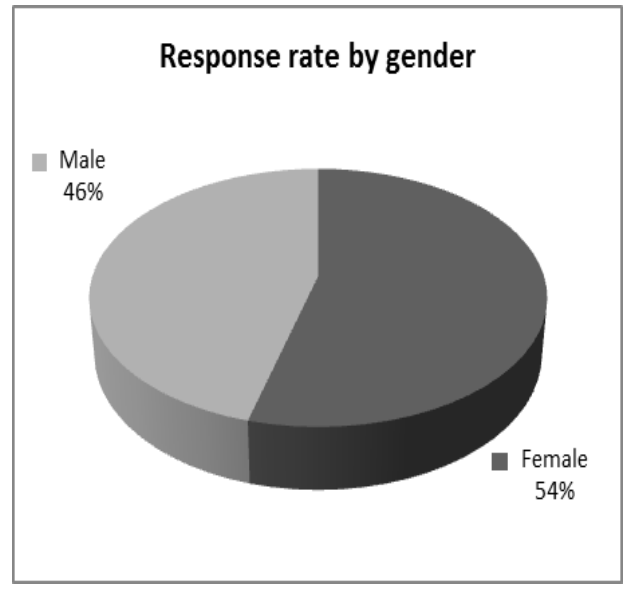

Figure 2: Response rate by gender

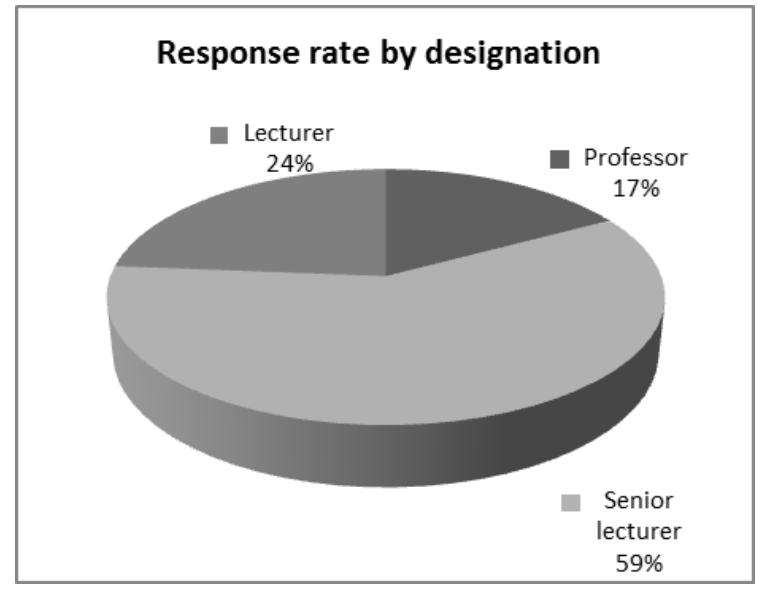

Figure 3: Response rate by designation 


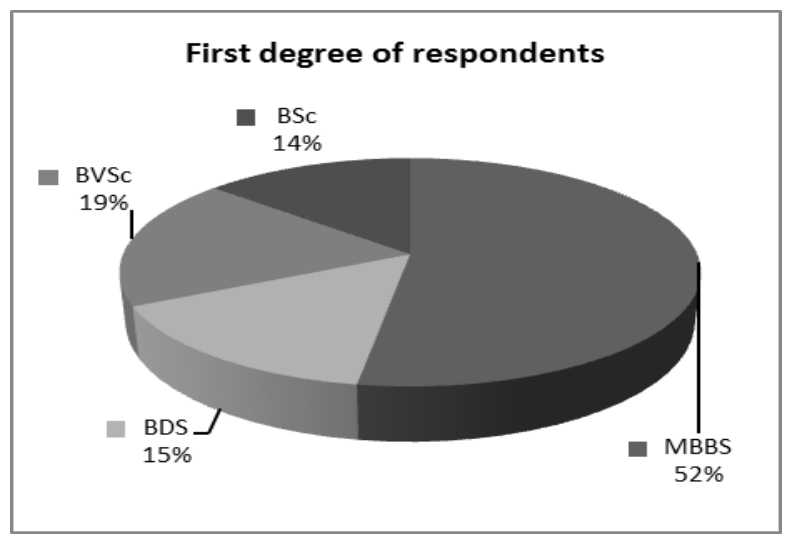

Figure 4: First degree of respondents

\section{Strategies Use in Information Needs}

Strategies use by the respondents in their information needs are shown in Figure 5 .There is no significant difference in percentages of respondents between groups by gender or by faculty or designation or qualifications regarding this issue.(calculated Chi-Square values were found at $\mathrm{p}>0.05)$.

According to Figure 6.2, the most favoured strategy by $100 \%$ of the respondent was using Internet. The library was little used. Respondents used personal collections of resources $(76 \%)$ than visiting library $(24 \%)$.

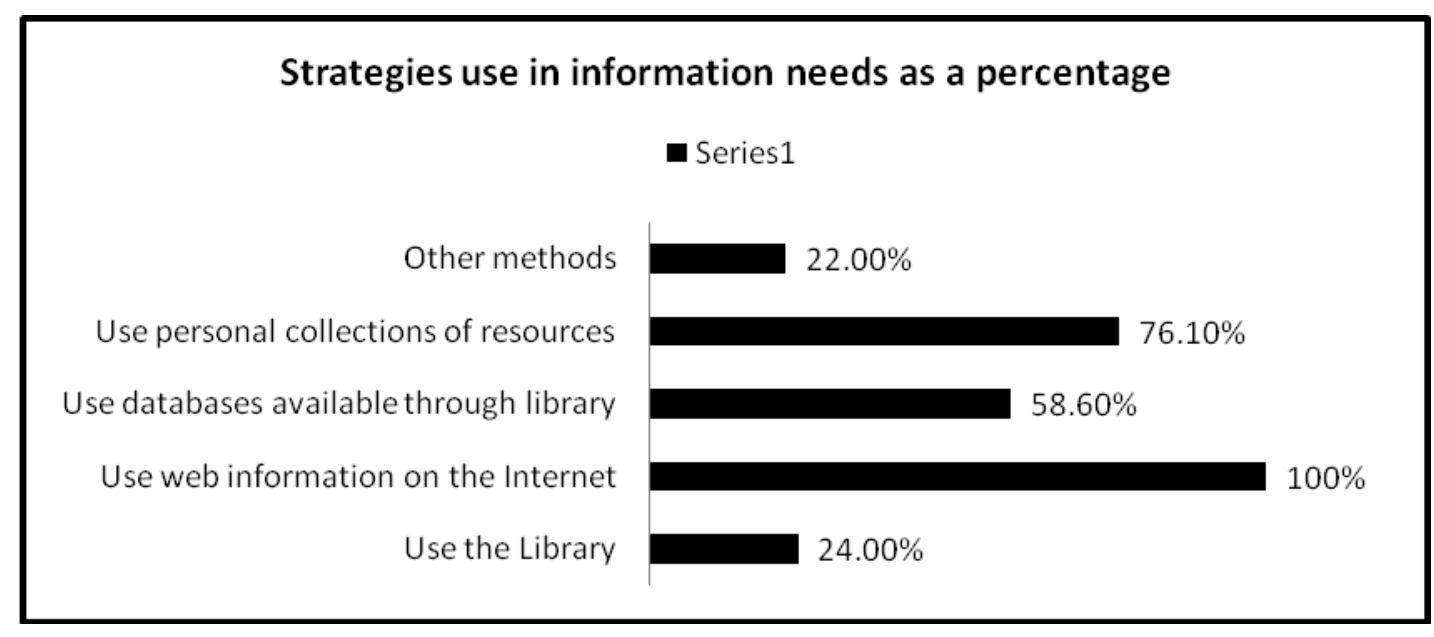

Figure 5 : Strategies use in information needs 


\section{Purpose of Seeking Information}

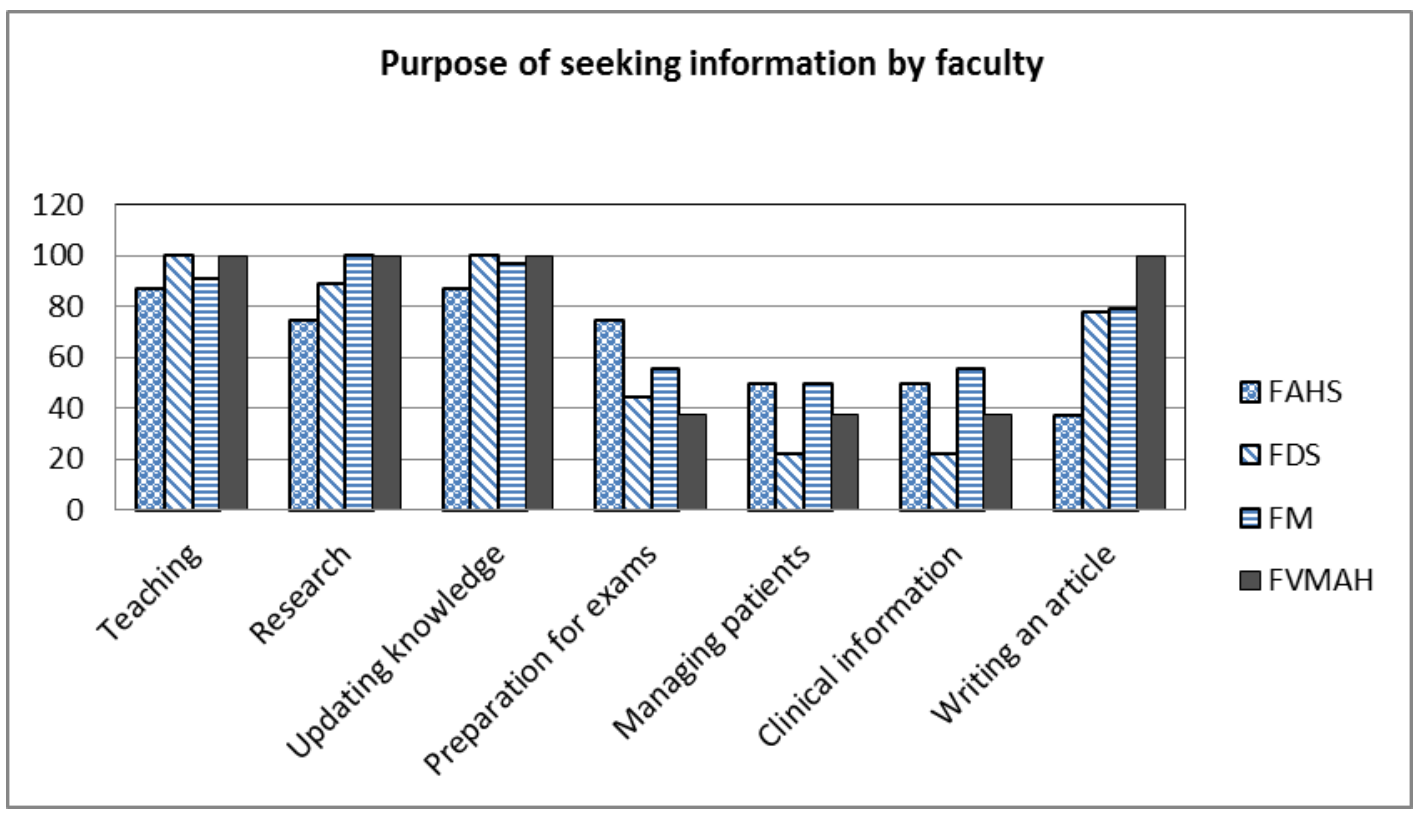

Figure 6: Purpose of seeking information by faculty

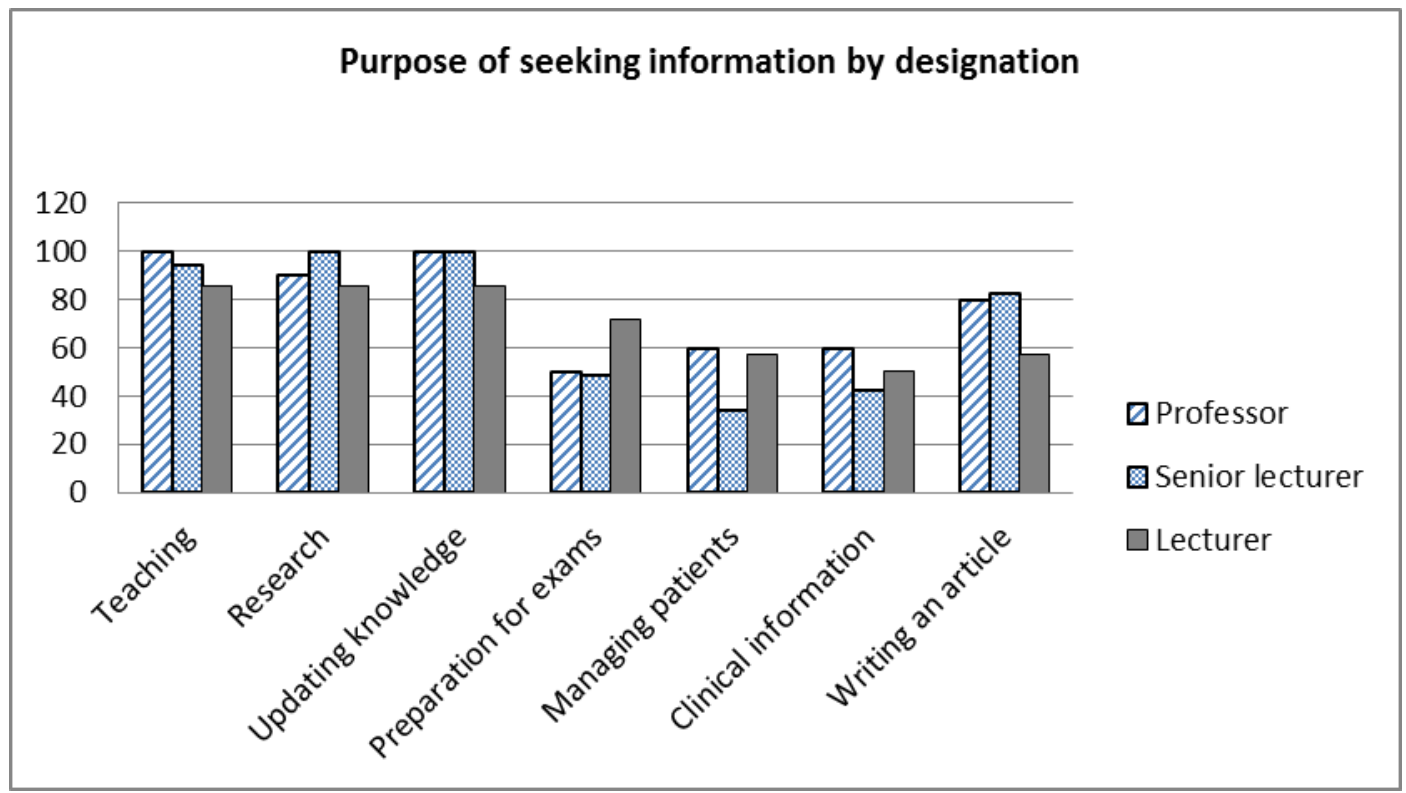

Figure 7: Purpose of seeking information by designation 
Purposes of seeking information of majority (90\%) of respondents as shown in Figures 6 and 7 were; teaching, research, updating knowledge and writing articles while percentages for 'managing patients' and 'clinical information' varied according to designation and faculty of the respondents. Percentages of respondents (by faculty) from FAHS (Figure 6) and lecturers by designation (Figure 7) were lagging behind other groups regarding writing articles as a purpose of seeking information. For a question asked about purpose of using Internet, all groups by designation showed the same pattern as that of 'purpose of seeking information' above. However the faculty-wise pattern showed that respondents from FAHS were lagging behind respondents from other faculties in the way that the Internet was used for research purpose and there was a significant difference (with a Chi-square value at $\mathrm{p}<0.05)$ in the percentages of usage. According to Figures 6 and 7 preparations for exams is one of the main purposes of respondents (all groups) from FAHS and particularly of lecturers by designation. It revealed that in some issues responses received from respondents of FAHS and respondents from the lecturer group showed the same pattern. One of the reasons would be that FAHS being a relatively young faculty, most of the academics are lecturers by designation. Further, due to lack of infrastructure facilities when compared to other faculties, access to Internet -based information is limited, thus usage of information resources by respondents from FAHS would be different from other faculties.

\section{Preference of Information Resource}

The most preferred types of resources of information by all groups; used by the majority of respondents were E-journals and Internet-based information as shown in Figures 8 and 9 'Professional colleagues' and 'case reports' have been selected by the respondents to a certain extent indicating that those were among the preferred resources by respondents. 


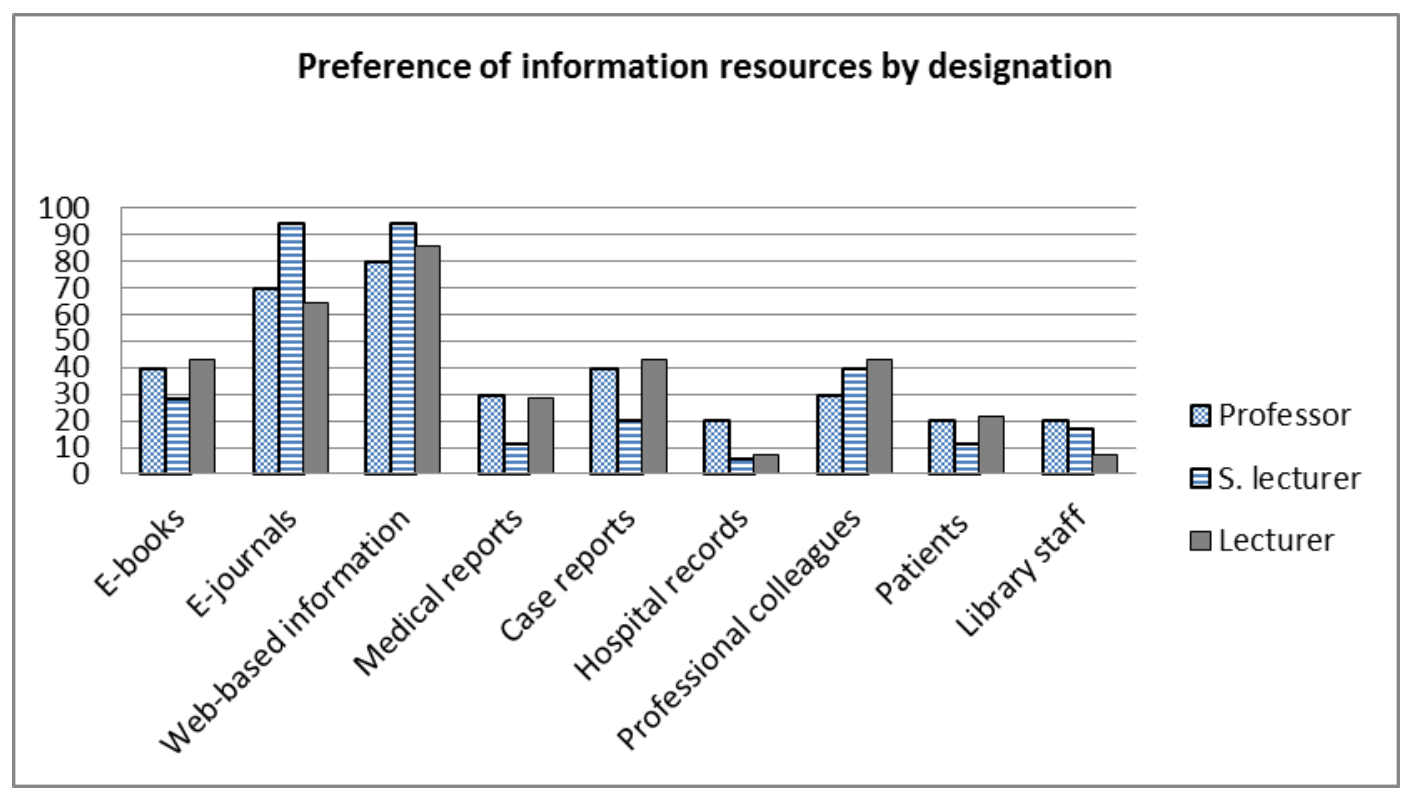

Figure 8: Preference of information resources by designation

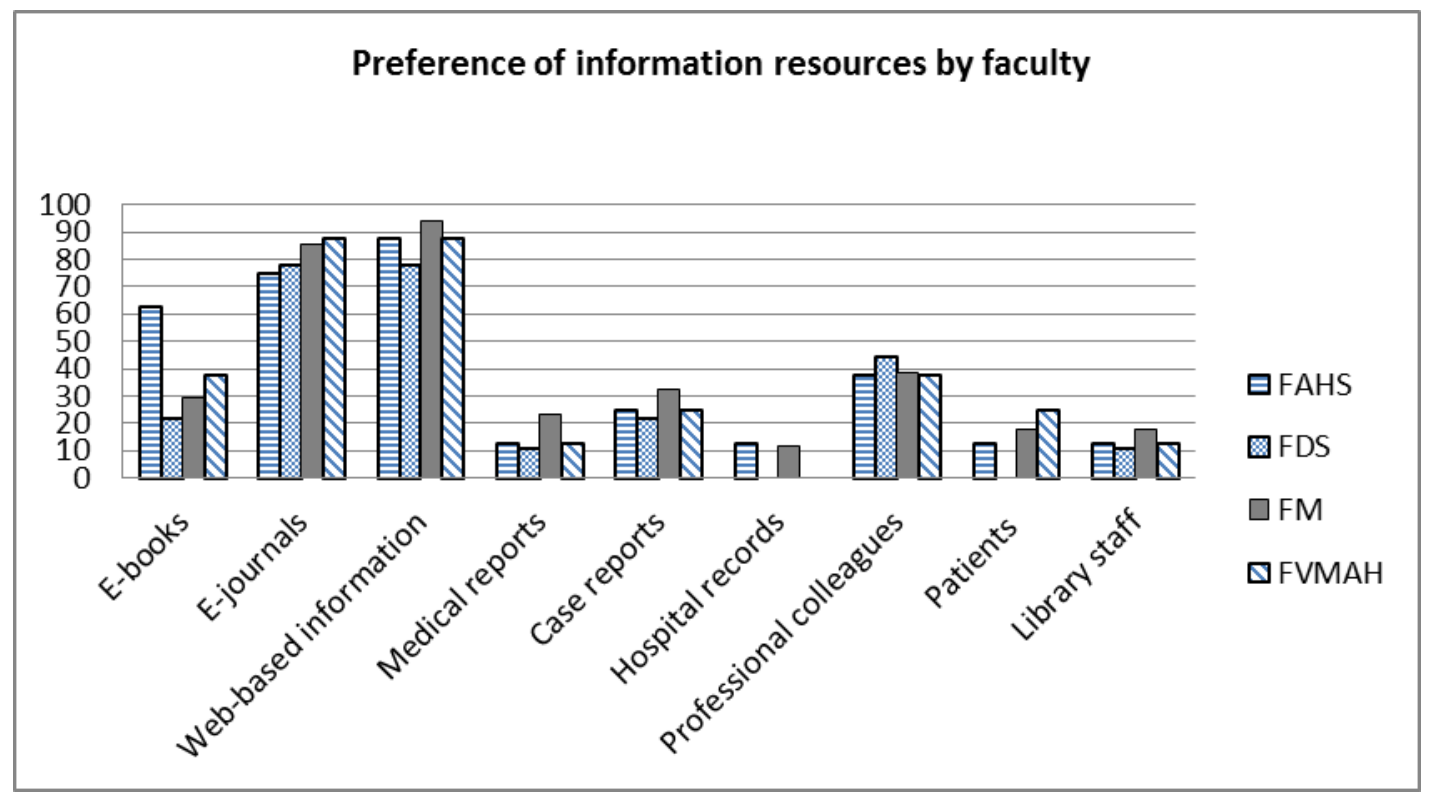

Figure 9: Usage of information resources by faculty 


\section{Usage of Internet-based Information}

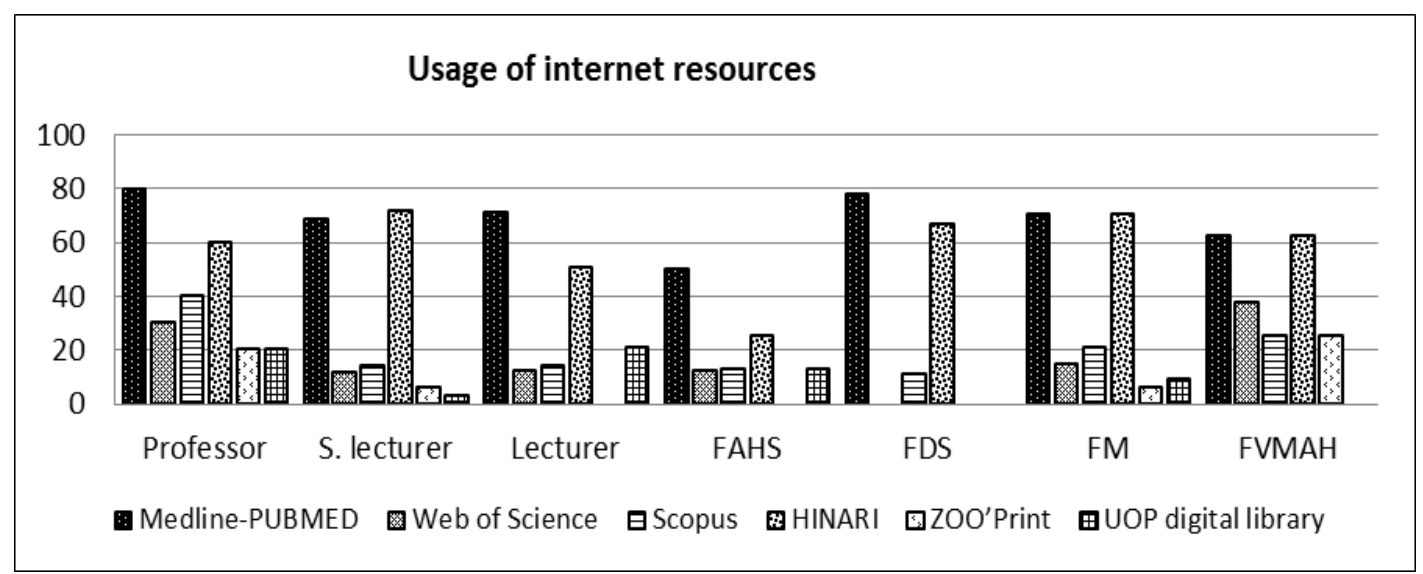

Figure 10: Usage of Internet resources

As shown in Figure 10, out of the databases available through university library web page, HINARI was the most used database and Medline-PUBMED was the most used resource while Zoo's Print was used mostly by respondents from FVMAH, mainly by professors. Web of Science and Scopus were used by the respondents to a certain extent. Response to a question on usage of some of the most popular resources among medical professionals such as Cancer Lit, Cochrane Reviews, Clinical Evidence, Up to date, and Clinical Trials which are available on the Web on subscription and of WHO database, showed no evidence of using the same by respondents. One of the main reasons for this would be the cost of the subscriptions. 


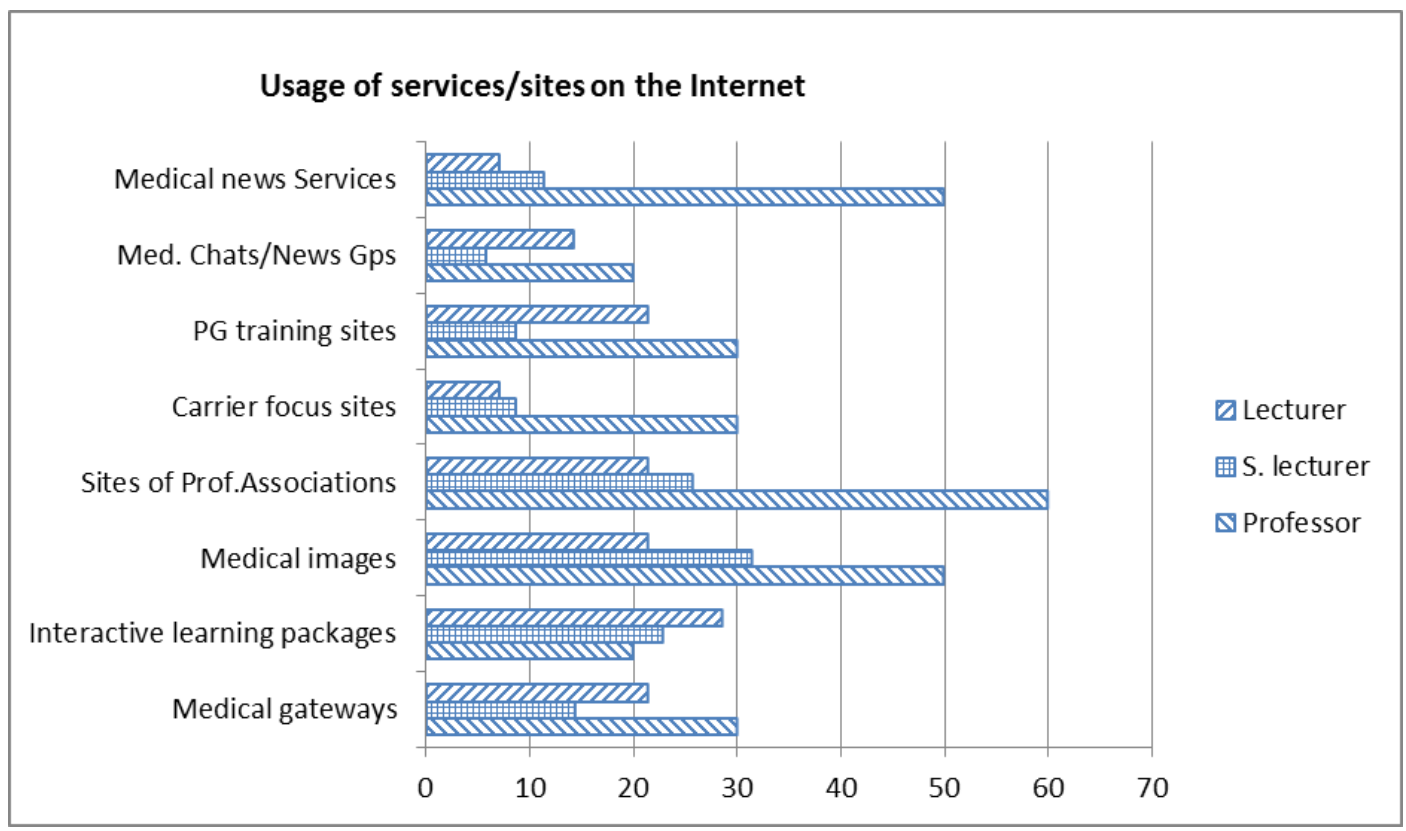

Figure 11: Usage of services/sites on the Internet

Pattern of usage of various services/sites on the Internet is depicted in Figure 11. Medical images, sites of professional associations and medical news services were mainly used by professors and to a considerable extent by other groups (senior lecturers and lecturers), while interactive learning packages were used by lecturers more than other groups. However, the difference in the pattern of usage of these services between groups is not statistically significant (with a Chi-square value at $\mathrm{p}>0.05$ ). Among search engines, 'Google search' was rated as the "most used" and "most versatile" search engine by $98 \%$ of all groups of respondents. During interviews it was revealed that Google scholar was the next useful tool after Google search.

\section{Usage of the Library}

The study revealed that the library was used frequently only by $24 \%$ of the respondents. Out of these library users $51 \%$ used it for reference, $58 \%$ to borrow books and $29 \%$ to consult journals. Sri Lanka collection and WHO collection in the Medical Library was consulted only by $18.6 \%$ and $14.3 \%$ respectively. There is no significant difference in the 
usage pattern of these library materials by different groups. It revealed that faculty libraries were used only by respondents of respective faculties except the Medical Library which is used by the majority (51\%) irrespective of their faculty. This is similar to the findings reported by Seneviratne (2004) regarding the libraries used by medical scientists in Kandy and Peardeniya where Medical Library of University of Peradeniya was used by all groups.

\section{Other Methods of Updating Knowledge}

For updating knowledge, more than $90 \%$ of respondents used public/guest lectures, conferences/seminars, research sessions and contacts with professional colleagues while $80 \%$ of them downloaded articles through colleagues abroad.

\section{Suggestions / Views through Free Comments}

Free comments revealed that free access to reputed online journals and online databases is the most demanding suggestion. Request for access to online core journals in their respective subjects was an outcry from many who made free comments. Replacing old computers in the E-library of FM with new computers with fast connectivity was another request made through these comments. The cost incurred, time taken to search through multiple resources to yield relevant information and lack of skills in techniques of information searching were identified as barriers in using web-based information resources. Further, request for assistance from library staff for database searching is highlighted.

\section{Conclusion}

When compared to findings of earlier studies to that of present study, it is evident that there is a clear change in the present scenario of information-seeking behaviour of academics/ scientists in the field of medicine and health sciences. A shift from library oriented information searching to Internet -based information searching is obvious. Findings of the present study reveals that it is the Internet; therefore, web based information is the strategy that is used most by the entire study population. A clear preference is shown for "Google search" by all groups may be due to its ability to search and yield results fast from multiple 
resources. Library is little used though HINARI database through library web page is used to a certain extent. Other online databases mentioned in the questionnaire are not used much; may be due to reasons such as cost incurred when not available free of charge, lack of awareness of the freely available resources, lack of skills to use it and time taken to yield results from a vast number of sources etc.. It appears that information-seeking behaviour of these academics varies between different groups in some issues such as purpose of seeking information and resources used. In conclusion, based on the findings of the study, improving access to Internet-based resources by providing 1) university-wide online access to reputed core journals and other essential resources , 2) computers with fast processors and better connectivity and 3) effective mechanisms to provide training in skills required by the academics to improve self-efficacy in information-seeking is recommended for future improvements. Introducing measures to increase the awareness of Open-Source information resources among academics is highly recommended. It is important that library professionals / information managers especially in health / medical libraries in universities should embark on re-designing their services with innovative approaches to match with the needs of health professionals of the time. While it may not be proper to generalize; these conclusions to entire study population as the rate of response is not quite satisfactory, the findings of the study can be considered as evidence for the general trend of informationseeking behavior of the targeted group.

\section{References}

Andrews, J. E., Pearce, K.A., Ireson, C. \& Love, M. M.(2005). Information-seeking behaviors of practitioners in a primary care practice-based research network. Journal of Medical Library Association, 93(2), 206-212.

Bennet, N. L., Casebeer, L.L., Robert E., Kristofco, MSW \& Strasseret, S.M. (2004). Physicians' Internet Information-Seeking Behaviors, The Journal of Continuing Education in the Health Professions, 24, 31-38.

Hider, P. N., Griffin, G., Walker, M., \& Coughlan, E.(2009).The informationseeking behavior of clinical staff in a large health care organization. Journal of Medical Library Association; 97(1), 47-50. 
Seneviratne, D.C. (2004). Information seeking behavior of medical scientists in Sri Lanka : a study of information needs and use of resources. Journal of the University Librarians' Association of Sri Lanka, 8, 1-12.

Thain, A. \& Wales A. (2003). Information needs of specialist healthcare professionals preliminary study based on the West of Scotland Colorectal Cancer Managed Clinical Network, Health Information and Libraries Journal, 22, 133-142.

Van der Voort, C.T.M., Swenne, C. A., van der Hoorn-van Velthoven, C.A.M. \& Belt, J.H.J. (2012). Online medical literature consultation habits of academic teaching physicians in the EU and CIS countries: A cross-sectional study, PLoS one, 7(11), published online 2012 November 2. DOI: 10.1371/journal.pone.0044302. 